\title{
An Overview of Sensitization Dynamics in Ferritic Stainless Steel Welds
}

\author{
M. O. H. Amuda and S. Mridha \\ Advanced Materials and Surface Engineering Research Unit, Department of Manufacturing and Materials Engineering, \\ International Islamic University Malaysia, P.O. Box 10, 50728 Kuala Lumpur, Malaysia \\ Correspondence should be addressed to M. O. H. Amuda, chatwivwale@yahoo.com
}

Received 26 December 2010; Accepted 27 April 2011

Academic Editor: F. J. M. Pérez

Copyright ( 2011 M. O. H. Amuda and S. Mridha. This is an open access article distributed under the Creative Commons Attribution License, which permits unrestricted use, distribution, and reproduction in any medium, provided the original work is properly cited.

\begin{abstract}
Besides the problem of low ductility and poor notch toughness of ferritic stainless steel welds due to the microstructure characteristics of the weld section as a result of the weld heat input rate and the heat transfer factor, susceptibility to intergranular corrosion caused by the depletion of the chromium content of the weld matrix particularly in the HAZ is a major concern limiting the full deployment of the material in certain engineering applications regardless of its attractive economics combined with moderate strength and excellent corrosion resistance in alkali and acidic environments. Several attempts had been made to solve the problem. In the present work, a generic review of the sensitization problem in ferritic stainless steel welds as well as remediation techniques is presented. While stabilization is the most practiced prevention technique, it appears that the control of weld heat input and by extension the cooling rate is the ultimate option to prevent the onset of sensitization and control susceptibility to intergranular corrosion; however, the specific range of welding current and speeds that forms the given range of weld heat input needs to be determined.
\end{abstract}

\section{Introduction}

Ferritic stainless steels are iron-chromium alloys with bodycentred cubic crystal structure having chromium content usually in the range of $11-30 \mathrm{wt} \%[1,2]$. These steels exhibit good ductility, formability, and moderately better yield strength relative to those of the austenitic grades, but the high temperature strength is somewhat poor [3]. Due to the crystal structure, the toughness is low at cryogenic temperature. Ferritic stainless steel is a candidate material in less severe corrosion atmosphere for chemical processing equipment, furnace parts, heat exchangers, petroleum refining equipment, recuperators, storage vessels, electrical appliances, solar water heaters, and household appliances [4]. They are particularly more appropriate in caustic and chloride environments [5].

However, despite these economic and metallurgical attributes, the ferritic stainless steels are less used in engineering application. This is because fusion welding of ferritic stainless steel particularly the first generation group AISI
430 is associated with many problems. These problems are grain coarsening in both the fusion zone and HAZ coupled with formation of grain boundary martensite in the weld, and these result in lower ductility and toughness in the weldment $[6,7]$. Other than these, susceptibility to intergranular corrosion caused by the depletion of the chromium content of the weld matrix in the HAZ vicinity is a major concern affecting the full deployment of the material in certain engineering application regardless of its attractive economics combined with moderate strength and excellent corrosion resistance in caustic and acidic environments. This susceptibility is broadly termed sensitization.

Sensitization is generally believed to promote stress corrosion cracking failure in some ferritic stainless steels $[8,9]$. Several models have been proposed to explain the sensitization of stainless steel; however, the chromium depletion model is the most widely accepted $[10,11]$.

Extensive studies have been undertaken to understand the mechanism, mode of sensitization and provides options for the control of the sensitization problem by ensuring that 
chromium remains in solution in the matrix [12]. Some of these studies include titanium or niobium stabilization of interstitial elements $(\mathrm{C}+\mathrm{N})$, control of ferrite number, and the use of low heat input during welding. The most successful scheme appears to be stabilization of the parent material with titanium or niobium combined with suitable design of overall composition to produce an effective high ferrite number. These schemes appear to be economically unviable for the average steel manufacturer particularly in thick ferritic stainless steel [12].

The cooling rate during welding has been provided as a factor that influences the desensitization of the ferrite phase through chromium backdiffusion into the depleted regions during cooling [13]. This suggests that energy input which invariably controls cooling rate during welding is a parameter that can influence the tendency of ferritic stainless steel to sensitize. The cooling rate is determined by the effective energy input per unit length of material and the energy transfer factor. For a given material, the higher the heat input, the slower the cooling rate.

Low-heat-input welding process has been suggested as having capacity to limit sensitization but not to eliminate it [14]. The welding heat inputs experienced by materials are process-determined. However, the range of heat inputs and cooling rates that optimized desensitization in ferritic stainless steel is hardly available in the literature, and welding process that practices such technique is equally not well reported. The fusion welding processes that approximate low-heat-input welding process are tungsten inert gas arc welding, laser welding, and hybrid TIG-Laser welding. These processes because of their very high power density induce low metallurgical distortion in workpiece and, therefore, produce higher quality welds than other processes. Lancaster [15] classified welding current range $50-170 \mathrm{~A}$ as low welding current; this implies that weld produced with welding current within this classification will likely produce low metallurgical distortion compared to welding current outside the range.

The present work attempts a generic review of sensitization in ferritic stainless steel welds as well as the remediation techniques that are industrially and commercially available.

\section{Theory of Sensitization in Ferritic Stainless Steel Welds}

The property of stainless steels particularly the ferritic grade is compromised when thermally treated in the temperature range greater than $900^{\circ} \mathrm{C}$, and as such it becomes readily prone to corrosive attack. This characteristic is generally referred to as sensitization. Thus, sensitization is describe as the susceptibility of $\mathrm{Fe}-\mathrm{Cr}-\mathrm{C}$ steels to intergranular corrosion when the chromium content of the surrounding matrix becomes depleted beyond the concentration necessary to maintain passivity of the steel. The depletion of the chromium content is indicated by the precipitation of chromium carbides on the grain boundaries as $\mathrm{M}_{23} \mathrm{C}_{6}$ or $\mathrm{M}_{7} \mathrm{C}_{3}$, producing a continuous depleted zone which is more susceptible to corrosion attack.

In fusion welding, this situation is approximated in the heat-affected zone (HAZ). Therefore, sensitization is essentially a HAZ phenomenon in fusion welding and has been reported as major cause of stress corrosion failure in most fusion-welded proprietary alloys [16-19]. At times, this is called high temperature embrittlement (HTE).

2.1. The Mechanism of Sensitization. The mechanism by which sensitization occur varies and contrasts. These are: (1) chromium depletion theory, (2) strain theory, (3) electrochemical theory, and (4) solute segregation theory.

The chromium depletion theory states that sensitization is promoted by the intergranular precipitation of chromiumrich $\mathrm{M}_{23} \mathrm{C}_{6}$-type carbides resulting in chromium depletion in the matrix adjacent to the precipitated carbides. If the depletion leads to reduce chromium level below the concentration required for passivation, then the material becomes sensitized to intergranular corrosion. The chromium depletion theory is supported by the work of Strawstron and Hillert [20] who observed good agreement between experimental and theoretical results.

The strain theory, however, presents a contradictory postulation to the chromium depletion mechanism. In the strain theory, severe plastic deformation at low temperature (cold work) leading to substantial increase in the dislocation density at the grain boundary compared to that in the matrix is believed to be the driving force for sensitization [21] The presence of such imperfect lattice structure containing dislocations, stacking faults, and so forth, enhances overall diffusion of alloying elements resulting in faster sensitization. Furthermore, the substantial plastic deformation in the stainless steel due to cold work increases the volume of dislocation pileups on slip plane. Consequently, slip planes become additional favorable sites for carbide precipitation within the grains and most often at the carbide-austenite interface. The strain energy associated with the dislocation density and pile-ups is restricted to a narrow region of the matrix-precipitate interface. The strain theory is reinforced by the observation of knife-line attack in a narrow band in the parent metal immediately adjacent to the weld on one side of the carbide-austenite interface. However, if chromium depletion theory were to be valid, the knife-line attack ought to have been on both sides of the weld and also uniform. The strain theory suggests that the knifeline attack is probably due to strain from distorted lattice adjacent to the carbide precipitate at the carbide-austenite or carbide-ferrite interface. In the strain theory, the rate of grain boundary attack is controlled by the orientation of the grain and the misorientation between the grains [22]. However, knife-line attack that is attributed to strain theory has not been observed in regions exposed to thermal cycle above $800^{\circ} \mathrm{C}$. And since sensitization in ferritic stainless steel welds is restricted to regions with thermal cycle higher than $800^{\circ} \mathrm{C}$, then the postulation of strain theory as the prevailing mechanism for sensitization is probably not valid. This is further strengthened by the reduction in the strain energy associated with the precipitation of carbides at this range of temperature [23]. If strain theory were to be responsible for sensitization, the strain energy ought to increase with increase in temperature leading to more dislocation pile ups and increased dislocation density. Rather what was observed 
was the healing out of dislocation pile ups. Also, the knifeline attack does not propagate in the absence of continuous grain boundary film.

The electrochemical theory on the other hand consider that a potential difference exists between the metallic carbide and the matrix, and that the metal carbide is more noble than the steel matrix, and hence, experiences accelerated intergranular attack particularly in the presence of residual stresses. However, Baumel et al. [24] in their work contradicted this theory because localized corrosion could not be confined to a very narrow zone, and that the corrosion must extend to the matrix. Also, an experimental potential measurement of 18-9 stainless steel, platinum, $\mathrm{M}_{23} \mathrm{C}_{6}$ and copper in Strauss solution showed that the potential of the four materials is nearly the same within an accuracy of $\pm 1 \%$. This observation was contrary to the result obtained on the effect of the electrolyte on the potential of $\mathrm{M}_{23} \mathrm{C}_{6}$ and austenite. This analysis indicates that the electrochemical theory is controversial and does not provide a better outlook of intergranular corrosion than predicted by the chromium depletion theory.

The solute segregation mechanism postulates that intergranular corrosion occurs in nonsensitized austenitic stainless steel when there is a continuous grain boundary path of a second phase, and soluble impurity segregates resulting from solute vacancy interactions. The mechanism was investigated on annealed material. The model was, however, concerned mainly with intergranular attack on nonsensitized steel and only secondarily with carbide forming sensitized steel. On the basis of this theory, resistance to intergranular attack is improved if discontinuous carbide are precipitated through heating between $800-900^{\circ} \mathrm{C}$ followed by water quenching. This theory has, however, been contradicted by the observation that the oxidizing power of the controlling environment is very important which does not permit the stainless steel to remain passive in the solution, and thus, general corrosion along with localized intergranular attack is likely to occur. Furthermore, it was observed that that the sigma phase precipitated at the grain boundaries in austenitic stainless steel 316 did not show acceleration of intergranular corrosion until the solution was made highly oxidizing. It appears that the solute segregation is only valid for non-sensitized steel and attempt to extend it to sensitized steel has not been successful because the tests were conducted in highly oxidizing solution where general as well as intergranular corrosion takes place. It has not been possible to isolate intergranular corrosion.

Therefore, from these discussions, it is apparent that the only mechanism whose experimental validation agrees with theory is chromium depletion mechanism, and this is supported by electron microprobe analysis and anodic polarization studies. It is, therefore, not surprising that the chromium depletion mechanism is the widely accepted theory [25].

\subsection{Manifestation of Sensitization in the Heat-Affected Zone.} Laboratory simulations and inservice inspection techniques [26] have established four different manifestations in stainless steels, and this has been confirmed in ferritic stainless

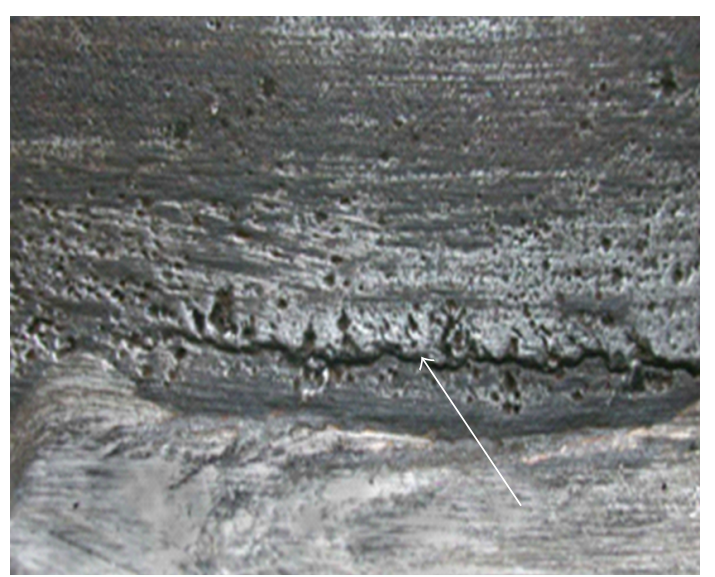

FIGURE 1: Mode 1 pitting and intergranular cracking (arrow) within the heat-affected zone of a weld deposited on incorrectly annealed base metal [13].

steel grades [13-27]. These manifestations are called modes and as such the four modes are mode 1 , mode 2 , mode 3 , and mode 4 , respectively. These modes differentiate the dynamics of the chromium depletion zones, in terms of where and how the zone will be formed, and the thermal consideration for the onset of chromium depletion process.

Mode 1: Sensitization due to Welding on Incorrectly Annealed Material. This occurs in single-pass weld and is linked to the presence of untempered martensite in the stainless steel before exposure to the sensitization temperature. Sensitization through this mode is usually characterized by pitting corrosion and intergranular cracking within the lowtemperature heat-affected zone (LTHAZ) a few millimeters from the weld interface as shown in Figure 1. Mode 1 is initiated when the material is inappropriately annealed into the dual-phase $(\alpha+\gamma)$ region above the $\mathrm{A}_{1}$ temperature during thermal treatment or any form of heat treatment before processing (this is referred to as double heating cycle) and this will produce substantial amount of untempered martensite particularly in the low-chromium ferritic stainless steel grade [12]. For instance, if a plate or edge of a coil is overheated during final annealing after hot strip rolling, the entire area is rendered susceptible to sensitization when welded. The sensitized zone can become very wide and extend along the entire length of the weld bead $[12,13]$.

Since mode 1 sensitization is caused by the presence of untempered martensite, it is best prevented by ensuring that the base metal does not contain any untempered martensite.

Mode 2: Sensitization in Welds with Overlapping HeatAffected-Zone. Sensitization via this mode presents similar mechanism to that described for mode 1 , and also requires the application of double heating cycle. However, the distinction in the two modes lies in how the untempered martensite is created [13]. While, in mode 1, the untempered martensite is produced as a result of incorrect annealing above $A_{1}$ temperature, it develops in mode 2 as a result of overlapping heat-affected zone formed on the deposition of 


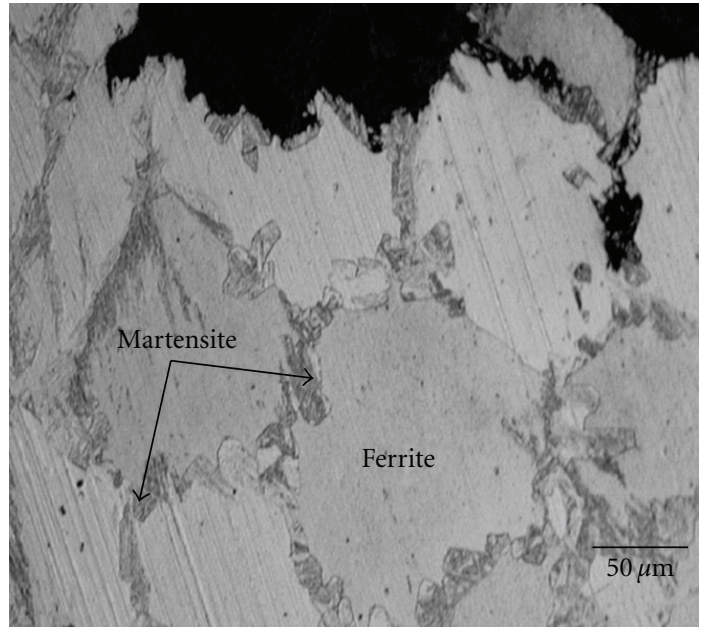

FIGURe 2: Preferential attack of the sensitized martensite phase in the HTHAZ of an overlay weld indicating Mode 2 sensitization [13].

multiple weld passes. In other words, for mode 1, single pass is sufficient to initiate sensitization whereas for mode 2 , at least two weld passes must be realized such that the first pass creates untempered martensite in the HAZ, and the critical sensitizing isotherm from the second pass causes carbide precipitation in the first HAZ [27]. The development of mode-2 type of sensitization depends on weld configuration, weld sequence, and the joint geometry. For instance, mode 2 sensitization has been observed at double fillet welds, double butt welds, repair welds, weld stop/start positions, and tack welds [6]. Figure 2 gives an illustration of mode-2 type of sensitization in ferritic stainless steel. A comprehensive treatment of mode 2 is available in [13].

Mode 3: Sensitization due to Continuous Cooling after Welding at Low Heat Input. This occurs in coarse-grained region adjacent to the fusion line in material where the HTHAZ is predominantly ferritic. Mode-3-type sensitization is independent of any previous heat treatment and material condition unlike modes 1 and 2. It occur when low heat input during welding leads to very fast cooling rates at the early stages of the weld thermal cycle. These rapid cooling rates can restrict or prevent austenite nucleation as the HAZ cools through the dual-phase $(\alpha+\gamma)$ field resulting in almost fully ferritic high-temperature heat-affected zone microstructure.

Though the ferrite at this stage contains more alloying elements than the low temperature alpha ferrite, the solubility drastically reduces at low temperature resulting in a ferritic structure that is supersaturated in carbon which ultimately undergo extensive carbide precipitation at the ferrite-ferrite boundary during cooling. Furthermore, the very fast cooling rates equally prevent the backdiffusion of chromium to the depleted regions adjacent to the chromiumrich carbides resulting in a continuous network of sensitized ferrite-ferrite grain boundaries as shown in Figure 3 (see the arrow in the figure).

The degree of sensitization in mode 3 depends on the metallurgical phase balance in the HTHAZ, and decreases

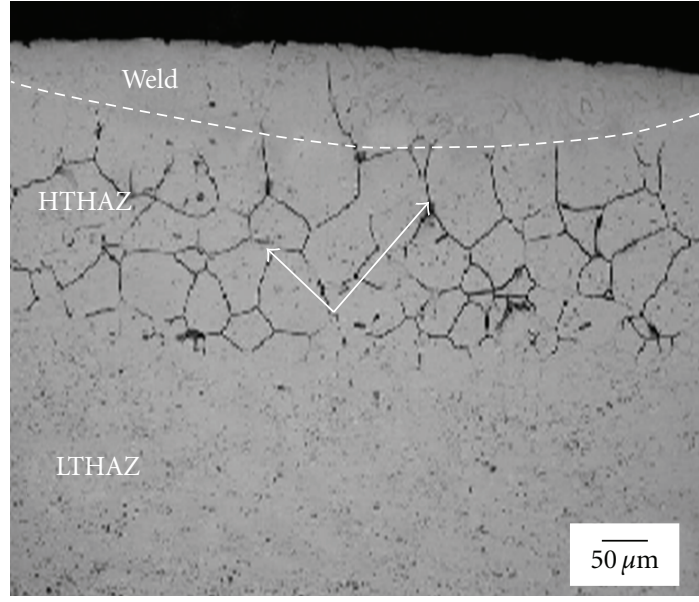

FIgURE 3: A continuous networks of ditched ferrite-ferrite grain boundaries in the HTHAZ due to mode 3 type sensitization [28].

significantly with increased volume fraction of austenite. The presence of enough austenite to absorb excess carbon ensures that a continuous network of chromium-depleted zone does not form and sensitization is prevented.

The composition of the steel combined with the cooling rate after welding determines the HTHAZ phase balance and hence, the degree of sensitization. Increasing the heat input during welding reduces the cooling rate and this ensures that more austenite forms in the heat-affected zone which eventually transforms to martensite at lower temperatures and it is retained down to room temperature as grain boundary martensite network within ferritic heat affected zone. Much slower cooling rate after welding at higher heat input level equally permits the ferrite to desensitize through diffusion of chromium from the interior grains into any chromium-depleted zones [28].

Furthermore, the chemical composition of steel influence the temperature over which austenite is stable and hence affects the HTHAZ phase balance. The amount of ferrite retained in the HTHAZ can be estimated using the equation provided by Kaltenhauser [18] and complemented by the equivalence equation of Balmforth and Lippold [29].

Mode 3 type sensitization can be prevented by ensuring that heat input levels during welding do not fall below around $0.5 \mathrm{~kJ} / \mathrm{mm}$ as well as having a material with high austenite potential to promote formation of austenite on cooling [30].

Mode 4: Sensitization on Welding at Excessive High Heat Input. In the earlier modes, sensitization is initiated either from untempered martensite, precipitated carbides (modes 1 and 2 ), or from rapid cooling sequence due to low welding heat input producing ferrite-ferrite sensitized region. In mode 4, however, the sensitization may occur under very slow cooling associated with welding at excessively high heat input. High temperature austenite may sensitize on cooling if the cooling rate is sufficiently slow. 
Mode 4 is the least common of all the four types. It normally exists within a narrow band at the border between HTHAZ and LTHAZ in the vicinity of $A_{1}$ peak temperature isotherm. The occurrence of sensitization with such a narrow band suggests that very specific conditions must be fulfilled for mode 4 sensitization to manifest. The onset of mode 4 sensitization is influenced by the cooling rate as well as the kinetics of the decomposition of austenite below the $\mathrm{A}_{1}$ temperature [13].

Du Toit et al. [13] suggested that mode 4 sensitization can be prevented by ensuring that welding heat does not exceed $1.5 \mathrm{~kJ} / \mathrm{mm}$.

It is clear from the preceding discussions that the level of the weld thermal cycle is a critical parameter in preventing the onset of sensitization of any kind in stainless steel particularly the ferritic grade. The thermal cycle is approximated by the peak temperature across the various points in the heat-affected zone, and this is related to the cooling rate. This probably indicates that both the weld thermal cycle and cooling rate apart from the material composition determines susceptibility to sensitization and its specific mode.

\section{Techniques for the Control of Sensitization}

The incidence of intergranular stress corrosion cracking within the heat-affected zone is closely linked to the depletion of chromium content of adjoining grain boundaries. It has been reported that at times, even in very weak solutions, sensitization may induce intergranular corrosion attack [8]. It is, therefore, important that the phenomenon is prevented rather than controlled once it creeps in. Several techniques have been explored, developed, and practiced commercially to prevent sensitization. These options are control of interstitial $(\mathrm{C}+\mathrm{N})$ element in steel, creating a high ferrite number, stabilization technique, and the control of heat input and cooling rate. Several techniques that had been implemented based on these options are evaluated in the next few sections.

3.1. Control of Interstitial Elements. Since sensitization is promoted by the precipitation of carbide and/ or nitrides at the grain boundaries due to the consumption of the matrix chromium by the interstitial constituents, then the reduction in the concentration of these elements to level permitted by stoichiometry equilibrium that can not initiate carbide precipitation is an attractive option, particularly in ferritic stainless steel where the solid solubility of carbon in iron is extremely low. It is recommended that interstitial elements in stainless steel should be less than $0.03 \mathrm{wt} \% \mathrm{C}$ [31].

However, due to the very low solubility of carbon in BCC ferrite carbide precipitation cannot be avoided. For instance, ferritic stainless steel containing interstitial $\mathrm{C}+\mathrm{N}$ greater than $1000 \mathrm{ppm}$ has been found to be inherently susceptible to intergranular corrosion (IGC) which is an indication of sensitization [5]. The limit of interstitial elements necessary to prevent intergranular corrosion is a function of chromium content and must necessarily be balanced against the weld ductility requirement. Demo [19] in his study established the interplay between IGC resistance and weld ductility as a function of chromium and interstitial contents. He showed that for $19 \mathrm{wt} \%$ chromium, the limit for interstitial C + $\mathrm{N}$ to prevent sensitization is $60-80 \mathrm{ppm}$ while with $35 \mathrm{wt} \%$ chromium, $\mathrm{C}+\mathrm{N}$ must not exceed $250 \mathrm{ppm}$.

It, however, must be stated that certain ferritic stainless steel with higher carbon content $(0.07 \mathrm{wt} \%)$ than the experimentally permissible $0.03 \mathrm{wt} \% \mathrm{C}$ containing appreciable amount of martensite provided better resistance to sensitization than similar material with lower carbon content [32]. This contradictory behaviour is due to the higher carbon ferritic steel forming about $10 \%$ austenite which absorbs the free carbon rejected by the ferrite. During the cooling cycle, the austenite formation is thermodynamically more favorable than carbide precipitation, thus, the remaining ferrite is very low in interstitial carbon. Though the presence of a small percentage of austenite may be beneficial in reducing sensitization, the high-carbon martensite which forms on cooling could have negative effect on the toughness of the steel.

In essence, while very low levels of interstitial element in stainless steel will reduce susceptibility to sensitization, this may not be practicable in fully ferritic stainless steel but with certain fraction of martensite.

3.2. Control of Ferrite Factor. The influence of ferrite factor in controlling sensitization in ferritic stainless steel was first reported by Kaltenhauser [18]. The ferrite factor is quite distinct from the ferrite number.

The ferrite number is basically used to estimate the ferrite content in the weld microstructure using magnetic measurement. The ferrite factor, on the other hand, is a scaling factor, based on the relative strength of ferrite-stabilizing and austenite-stabilizing elements, which predicts the tendency for ferritic microstructure to develop in welds. Kaltenhauser [18] derived an equation known as the Kaltenhauser ferrite factor (KFF) to determine the tendency to form martensite in weld metal. For low-chromium steels, the KFF is less than 13.5 and for medium-chromium steel, it is less than 17. The work established that higher ferrite factor than the determined KFF for a given alloy specification ensure that the steel is kept completely ferritic in the weld metal with improved corrosion resistance due to the absence of intergranular martensite, provided the interstitial element is within the permissible solubility level for ferritic stainless steel, otherwise, carbide precipitation cannot be avoided. The intergranular martensite induces residual stresses in the adjacent grain boundaries leading to poor impact resistance and accelerated initiation of cracks [12]. At that period when the KFF was developed, martensite in ferritic steel was considered deleterious. However, recent developments in ferritic stainless steel are aimed at reducing the ferrite factor in order to increase the austenite potential, thereby maximizing the martensite formed on cooling [33], and this produces significant grain refinement resulting in improved toughness of the material [12]. This is because the formation of martensite eliminates the presence of delta ferrite in the microstructure which is noted to be responsible for the 
degradation of toughness strength in the ferritic stainless steel welds [34].

It must be stated that toughness strength in ferritic stainless steel welds is generally influenced by both the grain size and the metallurgical factor. Therefore, martensite in welds provides dual benefits; it prevents grain growth and equally eliminates the presence of deleterious delta ferrite in the microstructure, and this combines to improve toughness in the weld [5]. However, the martensite must be a lowcarbon martensite to be effective in improving the weld toughness. Lakshminarayanan and Balasubramanian [35] reported improvement in the toughness of the weld section in friction stir welded $409 \mathrm{M}$ ferritic stainless steel and attributed the improvement to refined grain structure as well as the presence of martensite in the microstructure.

While it may be attractive to raise the austenite potential by increasing the interstitial content, this is counterproductive since high-carbon martensite needs to be tempered to restore toughness and ductility. This is a major shortcoming in the welding of ferritic stainless steel.

Fully martensitic structures other than inducing improved mechanical properties are also effectively immuned to sensitization because the $\mathrm{M}_{s}$ temperature for martensite is below the sensitization temperature, and at the critical temperature, the steel is austenitic.

Lula and Davis [32] studied two stainless steels with the same $17 \mathrm{wt} \%$ chromium but different austenite potentials. The one that formed $50 \%$ austenite at high temperature experienced less IGC relative to the second which formed $10 \%$ austenite. This is corroborated by the work of Sedriks [36] and Marshal [33] who stated that fully martensitic structure should be immuned to IGC because carbon precipitation will occur intragranularly and not on the grain boundaries.

Therefore, by the suitable adjustment of the KFF, sensitization can be drastically reduced and even eliminated.

3.3. The Use of Stabilization Technique. Resistance to IGC in austenitic stainless steel is enhanced through the addition of stabilizing elements. Since the mechanism of sensitization in austenitic stainless steel has been found applicable to ferritic stainless steel as well, then the stabilization technique adopted in austenitic stainless steel has also been applied to ferritic stainless steel. The stabilization treatment involves the addition of elements such as titanium and niobium during AOD/VOD steel-making process. These elements preferentially form stable MC-type carbides or nitrides which are thermodynamically more stable than the chromium carbonitrides. The use of zirconium had been reported [37-40], and other elements such as yttrium, vanadium, and tantalum had equally been suggested [41]. However, tantalum is quite expensive while vanadium is not effective due to the very slow vanadium carbonitride precipitation reaction [42, 43] combined with the fact that the dissolution temperature for vanadium carbides is relatively low at around $800^{\circ} \mathrm{C}$.

So far, titanium, niobium, or combinations of both have been used commercially to prevent sensitization. The use of titanium, however, comes with its disadvantages. Some of which are reduction in toughness and ductility due to the presence of large cubic precipitates, solid solution hardening, and poor surface finish of the steel sheet during production, and it is not suitable for material intended for application in strongly oxidizing conditions where the titanium precipitates are directly attacked and create the appearance of sensitization. Niobium on the other hand can overcome some of the shortcomings associated with titanium stabilization, but it is less effective because it forms carbide precipitates at lower temperature. This apparently explains why dual stabilization is rather the norm.

Dundas and Bond [44] conducted stabilization study on $18 \mathrm{Cr}-2 \mathrm{Mo}$ and $26 \mathrm{Cr}-\mathrm{Mo}$ ferritic stainless steel alloy and proposed that the minimum titanium content should satisfy (1)

$$
\mathrm{Ti}=0.2 \%+4 *(\mathrm{C}+\mathrm{N})
$$

where $\mathrm{C}, \mathrm{N}=$ interstitial concentration of carbon and nitrogen, respectively, in wt $\%$, and $\mathrm{Ti}=$ minimum titanium content.

Fritz and Franson [45] improved (1) and proposed a new formula (2) incorporating the stabilization effect of niobium

$$
\mathrm{Ti}+\mathrm{Nb}=0.08 \%+8 *(\mathrm{C}+\mathrm{N}) .
$$

Devine and Ritter [46], however, contrasted the inclusion of nitrogen in the equation and rather maintained that sensitization resistance was solely dictated by carbon concentration with very little influence from nitrogen.

EDX analysis of extracted precipitates revealed lower chromium content in nitrides relative to carbides; therefore, this implied that the effect of nitrogen should be less severe than that of carbon, and their relative contribution should not be at par. It becomes apparent therefore, that (2) should be modified as given in

$$
\mathrm{Ti}+\mathrm{Nb}=0.08 \%+8 *(x \mathrm{C}+\mathrm{N}),
$$

where $x(>1)$ is the coefficient for the greater influence of carbon on sensitization than nitrogen.

However, sensitization is still possible in properly stabilized alloys, particularly at extremely rapid cooling rate as experienced during the cooling cycle of fusion welding. This is reported by Williams and Babaro [47] in their work.

3.4. Control of Weld Heat Input and Cooling Rate. Several studies $[13,48,49]$ have been undertaken on the contribution of the thermal history to the degree of sensitization in different grades of stainless steel, particularly the influence of weld heat input and by extension the cooling rate. These steels have different sensitization densities depending on the phase balance. The results of these studies appear to be confusing and contrasting. For instance, the result of the investigation of weld heat input on austenitic is not applicable to ferritic because they exhibit different metallurgies and transformation kinetics. However, for ferritics, it has been established that low heat inputs welding results in very fast cooling rates during the early stages of the weld thermal cycle, and these can suppress austenite nucleation at the 
HTHAZ as the HAZ cools through the dual-phase $(\alpha+$ $\gamma$ ) field producing practically fully ferritic microstructures. Since the solubility of carbon in ferrite is very low, the phase becomes supersaturated in carbon. This produces extensive carbide or nitride precipitation at the ferrite-ferrite grain boundaries during the cooling cycle. Beside the precipitation of carbides at the grain boundary, fast cooling rates equally prevent back-diffusion of chromium to the depleted regions adjacent to the chromium-rich carbides; creating a network of sensitized ferrite-ferrite grain boundaries [13]. As weld heat input during welding increases, the regions in the HAZ experiences temperature in the region of $1300^{\circ} \mathrm{C}$ and higher at which the steel is fully ferritic with the interstitial elements in solid solution, fast cooling produces significant $\mathrm{Cr}_{23} \mathrm{C}_{6}$ or $\mathrm{Cr}_{2} \mathrm{~N}$ precipitation [48]. However, if the cooling rate is slower, for instance, in a high heat input process, austenite forms and interstitial elements diffuse to and dissolve in the austenite, thus, reducing the amount of interstitial precipitates. At lower temperatures around $800-500^{\circ} \mathrm{C}$, the austenite transforms to martensite and is retained down to room temperature as grain boundary martensite within a ferritic heat-affected zone microstructure [13].

The amount of carbon retained in the martensite depends on the cooling rate. Martensite formed on fast cooling rate retains higher levels of the carbon in supersaturated solid solution. At slower rates, the formation of martensite is preceded by carbide precipitation in the austenite, and less carbon is retained in solution in the martensite phase. Therefore, the cooling rate needs to be balanced with the metallurgical phase fraction desired in a weld to prevent the onset of sensitization. Thus, it appears that high weld heat input rates producing slower cooling rates is very essential to reducing and/or controlling sensitization in ferritic stainless steel. This is because these conditions permits healing of chromium-depleted regions around the precipitate. This is phenomenally referred to as desensitization. Beside this, high heat input rate ensuring slower cooling rates produces higher austenite volume fractions taking more interstitials into solution with the consequent decrease in the amount of carbonitrides precipitation in the ferrite and hence sensitization is controlled.

However, excessive heat input also increases sensitization density. While in low heat input (fast cooling rate), precipitation starts at $\alpha / \gamma$ boundary near the fusion line, in the slow cooling resulting from excessive heating, precipitates are formed at the $\alpha / \gamma$ boundaries on the HAZ at a distance of about $3 \mathrm{~mm}$ from the fusion zone [48]. Sridhar et al. [49], based on the series of their work, optimized weld heat input within the range $0.5-1.5 \mathrm{~kJ} / \mathrm{mm}$ though the recommended upper range in most literature is $1 \mathrm{~kJ} / \mathrm{mm}$ [8], but the weld heat input must never be less than $0.5 \mathrm{~kJ} / \mathrm{mm}$ [13]. However, the spectrum of welding current and speed that forms this range of optimized weld heat input needs to be determined.

\section{Conclusions}

An overview of sensitization dynamics in ferritic stainless steel welds has been provided. The welds are prone to HAZ sensitization under very specific conditions and may suffer from intergranular and stress corrosion cracking in the HAZ when exposed to corrosive environments.

Several mechanisms have been explored to explain the dynamics of sensitization, but the chromium depletion theory has been the only one proved experimentally.

The dynamics manifests in four different modes depending on the initial microstructure of the parent steel, the number of weld passes, the level of heat input during welding, and the type of phase sensitized. Modes 1 and 2 prevails when martensite is sensitized irrespective of the weld heat input, however, the condition for sensitization in the two is quite distinct. Mode 1 occurs when the parent metal consisting of dual-phase ferrite-martensite microstructure is welded usually in a single pass welding, whereas, mode 2 results when multiple pass welding is employed such that the $\mathrm{HAZ}$ of the second pass overlaps that of the first. On the other hand, modes 3 and 4 are HTHAZ phenomenon involving sensitization of delta ferrite and austenite, respectively, at different heat input conditions. Mode 3 manifests when delta ferrite is sensitized within the high-temperature heataffected zone during fast cooling after welding at low heat input. In mode 4, however, austenite is sensitized within the high-temperature heat-affected zone but after welding at excessively high input levels greater than $1.5 \mathrm{~kJ} / \mathrm{mm}$.

Sensitization is controlled using different initiatives ranging from control of interstitial elements $(\mathrm{C}+\mathrm{N})$ to level usually less than 0.03 wt $\%$ through ensuring higher austenite potential and the use of dual stabilization involving principally titanium and niobium to the control of weld heat input within the range $0.5-1.5 \mathrm{~kJ} / \mathrm{mm}$. The control of weld heat input appears to be the ultimate option; however, the specific range of welding current and speeds that forms the given range of weld heat input needs to be determined.

\section{References}

[1] V. Balasubramanian, K. Shanmugan, and A. K. Lakshminarayanam, "Effect of autogenous arc welding processes on fatigue crack growth behavior of ferritic stainless steel joints," Iron and Steel Institute of Japan International, vol. 48, no. 4, pp. 489-495, 2008.

[2] D. Kotecki, "Ensuring the stamina of stainless steel," Welding Journal, vol. 77, no. 11, pp. 41-45, 1998.

[3] D. Pecker and I. M. Bernstein, Handbook of Stainless Steel, McGraw Hill, New York, NY, USA, 1977.

[4] B. Holmber, "Stainless steel: their properties and suitability for welding, bronchure, avestapolarit welding," 2009, http:// www.outokumpu.com/applications/upload/pubs_113155252 .pdf.

[5] J. C. Lippold and D. J. Kotecki, Welding Metallurgy and Weldability of Stainless Steel, Wiley-Interscience, Hoboken, NJ, USA, 2005.

[6] G. M. Reddy and S. D. Meshran, "Grain refinement in ferritic stainless weld through magnetic arc oscillations and its effect on tensile property," Indian Welding Journal, vol. 39, no. 3, pp. 35-41, 2006.

[7] G. M. Reddy and T. Mohandas, "Explorative studies on grain refinement of ferritic stainless steel welds," Journal of Materials Science Letters, vol. 20, no. 8, pp. 721-723, 2001.

[8] L. M. Matthews, B. Griesel, P. T. Longman, G. T. Van Rooyen, and J. M. Prozzi, "Sensitization in low-carbon 12\% 
chromium containing stainless steel," in Proceedings of the 14th International Corrosion Congress, p. 332, Cape town, South Africa, 1999.

[9] R. Nishimura, "Stress corrosion cracking of type 430 ferritic stainless steel in chloride and sulfate solutions," Corrosion, vol. 48, no. 11, pp. 882-890, 1992.

[10] A. P. Bond, "Mechanism of intergranular corrosion in ferritic stainless steels," Transactions of the Metallurgical Society of American Institute of Mining, Metallurgical, and Petroleum Engineers, pp. 2127-2134, 1969.

[11] J. J. Demo, "Mechanism of high temperature embrittlement and loss of corrosion resistance in AISI type 446 stainless steel," Corrosion, vol. 27, no. 12, pp. 531-544, 1971.

[12] M. N. Van Warmelo, Susceptibility of $12 \% \mathrm{Cr}$ steels to sensitization during welding of thick gauge plate, M.S. thesis, University of Wollongong, Australia, 2007.

[13] M. Du Toit, G. T. Van Rooyen, and D. Smith, An Overview of the Heat-Affected Zone Sensitization and Stress Corrosion Cracking Behavior of 12\% Chromium Type 1.4003 Ferritic Stainless Steel, IIW Doc IX-H-640, 2006.

[14] C. Gobler, Weldability studies on $12 \%$ and $14 \%$ chromium steels, Ph.D. thesis, University of Pretoria, South Africa, 1987.

[15] J. F. Lancaster, Metallurgy of Welding, Chapman \& Hall, London, UK, 5th edition, 1993.

[16] M. Streicher, "The role of carbon, nitrogen and heat treatment in the dissolution of Iron-chromium alloys in acids," Corrosion, vol. 29, no. 9, pp. 337-360, 1973.

[17] M. Semchysen, A. P. Bond, and H. J. Dunda, "Effects of composition on ductility and toughness of ferritic stainless steel," in The Metallurgical Evolution of Stainless Steel, F. B. Pickering, Ed., pp. 260-273, ASM, 1972.

[18] R. H. Kaltenhuser, "Improving the engineering properties of ferritic stainless steel," Metals Engineering Quarterly, vol. 11, no. 2, pp. 41-47, 1971.

[19] J. J. Demo, "Weldable and corrosion resistant ferritic stainless steels," Metallurgical Transactions A, vol. 5, no. 11, pp. 22532256, 1974.

[20] C. Strawström and M. Hillert, "An improved depleted zone theory of intergranular corrosion of 18-8 stainless steel," Journal of Iron andSteel Institute, vol. 207, no. 1, pp. 77-85, 1969.

[21] N. Parvathavarthimu, "Sensitization and testing for intergranular corrosion," in Corrosion of Austenitic Stainless Steel: Mechanism, Mitigation and Monitoring, H. S. Khatak and B. Raj, Eds., pp. 117-138, Woodhead, London, UK, 2002.

[22] Z. Ahmad, Principles of Corrosion Engineering and Corrosion Control, Institution of Chemical Engineers, ButterworthHeinemann, Oxford, UK, 2006.

[23] J. R. Davis, "Corrosion behavior," in Stainless Steels: An ASM Specialty Handbook, pp. 133-238, ASM International, Materials Park, Ohio, USA, 1996.

[24] A. Baumel, H. E. Buhler, H. J. Schuller et al., "Interpretation of the causes of intergranular corrosion of stainless steels in connection with the chromium depletion theory," Corrosion Science, vol. 4, no. 1-4, pp. 89-103, 1964.

[25] V. Cihal, "Intergranular corrosion of steels and alloys," Materials Science Monographs, vol. 18, pp. 79-83, 1984.

[26] H. Tomari, K. Fujiwara, K. Shimogori, T. Fukuzuka, and M. Kanda, "Intergranular stress corrosion cracking of $13 \%$ and $18 \%$ Cr ferritic stainless steels in high temperature purity water," Corrosion, vol. 38, no. 5, pp. 283-294, 1982.

[27] M. Warmelo, D. Nolan, and J. Norish, "Mitigation of sensitization effects in unstabilized $12 \%$ Cr ferritic stainless steel weld," Materials Science and Engineering A, vol. 464, pp. 157$169,2007$.

[28] M. L. Greeff and M. Du Toit, "Looking at the sensitization of $11-12 \%$ chromium EN 1.4003 stainless steels during welding," Welding Journal, vol. 85, no. 11, pp. 243s-251s, 2006.

[29] M. C. Balmforth and J. C. Lippold, "New ferritic-martensitic stainless steel constitution diagram," Welding Journal, vol. 79, no. 12 , pp. 339 s-345s, 2000.

[30] J. G. Williams and F. J. Barbaro, "Sensitization and intergranular stress corrosion cracking of the HAZ of welded $12 \% \mathrm{Cr}$ ferritic stainless steels," Australasian Welding Journal, vol. 50, no. 4, pp. 212-218, 2005.

[31] T. G. Gooch, "Corrosion behavior of welded stainless steel," Welding Journal, vol. 75, no. 5, pp. 135s-154s, 1996.

[32] R. A. Lula and J. A. Davis, "Intergranular corrosion cracking in $12 \%$ Cr ferritic stainless steels," in Intergranular Corrosion of Stainless Alloys, R. F. Stegerwald, Ed., pp. 233-247, ASTM STP 656, 1978.

[33] A. W. Marshal and J. C. M. Famar, "Welding of ferritic and martensitic 11-14\% Cr steels," IIW document, IXH-494-200, pp. 1-39, 2000.

[34] E. Folkhard, Welding Metallurgy of Stainless Steel, Springer, New York, NY, USA, 1988.

[35] A. K. Lakshminarayanan and V. Balasubramanian, "An assessment of microstructure, hardness, tensile and impact strength of friction stir welded ferritic stainless steel joints," Materials and Design, vol. 31, no. 10, pp. 4592-4600, 2010.

[36] A. J. Sedriks, "Effects of alloy composition and microstructure on the passivity of stainless steels," Corrosion, vol. 42, no. 7, pp. 376-389, 1986.

[37] J. L. Cavazos, "Characterization of precipitates formed in a ferritic stainless steel stabilized with $\mathrm{Zr}$ and Ti additions," Materials Characterization, vol. 56, no. 2, pp. 96-101, 2006.

[38] N. Shigenaka, S. Ono, Y. Isobe, T. Hashimoto, H. Fujimori, and S. Uchida, "Effect of zirconium addition to austenitic stainless steels on suppression of radiation induced chromium segregation at grain boundaries under ion irradiation," Journal of Nuclear Science and Technology, vol. 33, no. 7, pp. 577-581, 1996.

[39] R. G. Nooning Jr., Effect of stabilizing elements on the precipitation behavior and phase stability of type 409 ferritic stainless steels, M.S. thesis, University of Pittsburgh, 2002.

[40] W. Gordon and A. Van Bennekom, "Review of stabilisation of ferritic stainless steels," Materials Science and Technology, vol. 12, no. 2, pp. 126-131, 1996.

[41] A. A. Ogwu and T. J. Davies, "Improving the sensitisation resistance of ferritic stainless steels," Scripta Materialia, vol. 37, no. 3, pp. 259-263, 1997.

[42] O. Bletton, J. Bayol, and P. Terrien, "Martensitic stainless steel with improved machinability," 2009, http://www.freepatentsonline.com/5427635.html.

[43] V. S. Yarkovoi, "Thermodynamic analysis and intergranular corrosion of corrosion-resistant chrome-manganese steels with nitrogen," Metal Science and Heat Treatment, vol. 35, no. 5, pp. 273-277, 1993.

[44] H. J. Dundas and A. P. Bond, "Niobium, titanium requirements for stabilization of ferritic stainless steels," in Intergranular Corrosion of Stainless Steels, R. F. Stegerwald, Ed., pp. 154178, ASTM STP 656, 1978.

[45] J. D. Fritz and I. A. Franson, "Sensitization and stabilization of type 409 ferritic stainless steel," Materials Performance, vol. 36, no. 8, pp. 57-61, 1997.

[46] T. M. Devine and A. M. Ritter, "Sensitization of $12 \mathrm{Wt}$ Pct chromium, titanium-stabilized ferritic stainless steel," 
Metallurgical Transactions A, vol. 14A, no. 8, pp. 1721-1728, 1983.

[47] J. G. Williams and F. J. Barbaro, "Susceptibility and prevention of HAZ sensitization and intergranular stress corrosion cracking in various $12 \%$ Cr steels," in Proceedings of the Iron and Steel Technology Conference (AIstech '05), Charlotte, NC, USA, May 2005.

[48] J. W. Fourie and F. P. A. Robinson, "Literature review on the influence of weld-heat inputs on the mechanical and corrosion properties of duplex stainles steels," Journal of The South African Institute of Mining and Metallurgy, vol. 90, no. 3, pp. 59-65, 1990.

[49] N. Sridhar, L. H. Flasche, and J. Kolts, "Effects of welding parameters on mechanical properties and corrosion of duplex stainless steels," in New Developments in Duplex Stainless Steel Technology, R. A. Lula, Ed., pp. 341-350, ASM International, Materials Park, Ohio, USA, 1984. 

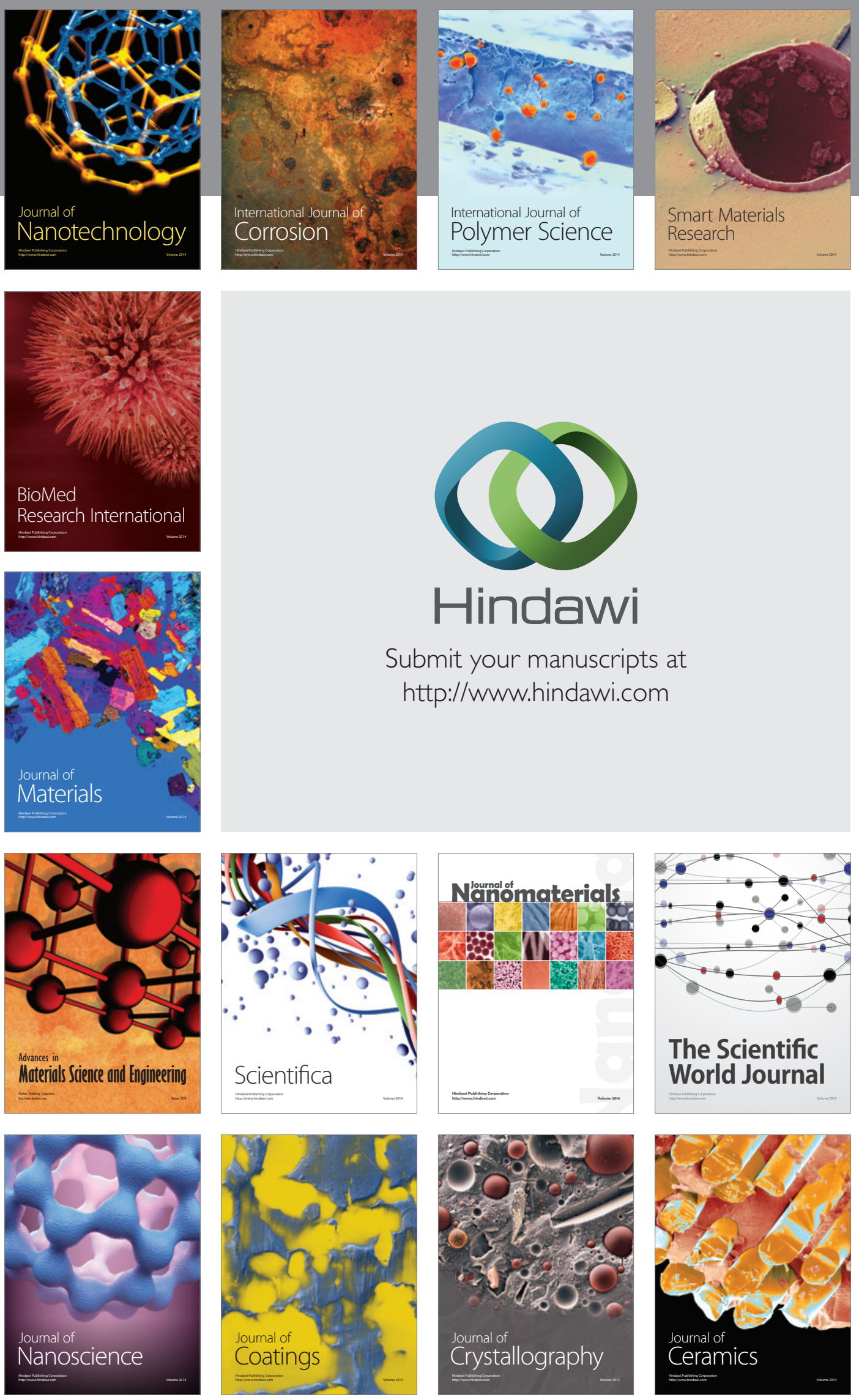

The Scientific World Journal

Submit your manuscripts at

http://www.hindawi.com

\section{World Journal}

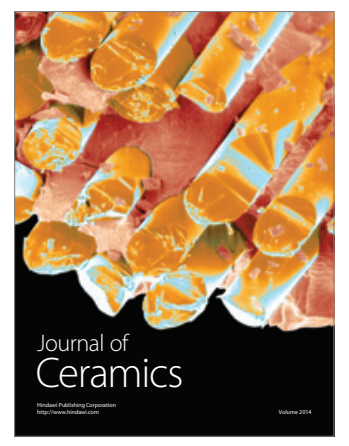

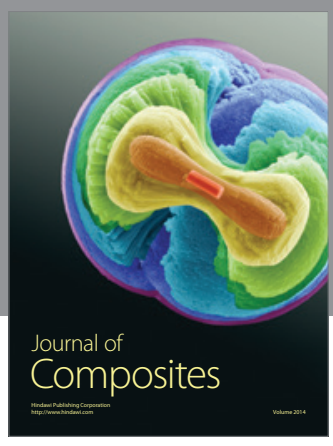
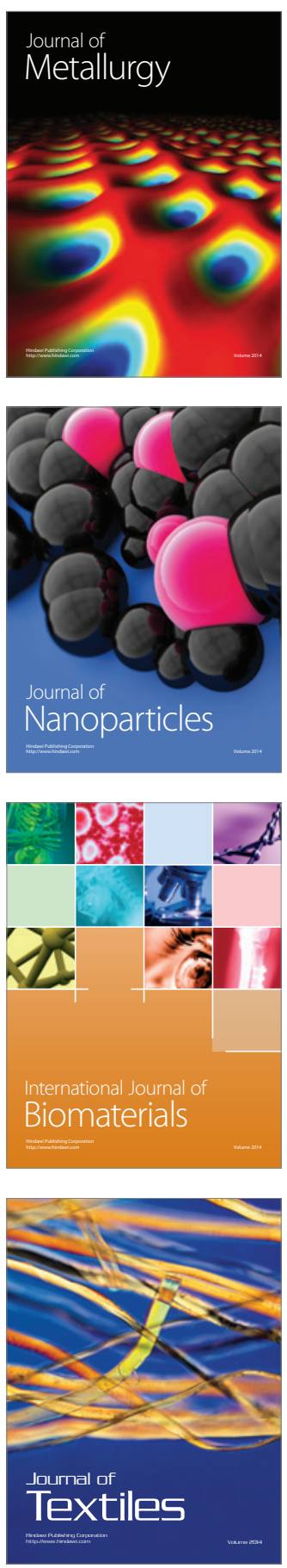